\title{
Barium isotope calibrations between shallow-water corals and in-situ seawater
}

\author{
YU-TE ALAN HSIEH ${ }^{1}$, ROB PAVER ${ }^{1}$, JANI T.I. TANZIL ${ }^{2}$, \\ LUKE BRIDGESTOCK ${ }^{1,3}$, JEN N. LEE ${ }^{4}$ AND GIDEON M \\ HENDERSON $^{1}$ \\ ${ }^{1}$ University of Oxford \\ ${ }^{2}$ National University of Singapore \\ ${ }^{3}$ Department of Earth Sciences, University of Cambridge \\ ${ }^{4}$ University of Malaysia Terengganu \\ Presenting Author: yu-te.hsieh@earth.ox.ac.uk
}

Barium incorporated in coral skeletons has been widely used as a paleo proxy to study terrestrial inputs, upwelling and anthropogenic activities in marine environments. However, these applications often face the challenges of poor replication in the coral skeletal $\mathrm{Ba} / \mathrm{Ca}$ records from multiple coral colonies and complex Ba sources in coastal environments. Recent studies of $\mathrm{Ba}$ isotopes in seawater and deep-sea corals have demonstrated the potential to trace $\mathrm{Ba}$ sources and water mixing in the ocean $[1,2]$, but there is a lack of in-situ seawater calibrations for Ba isotopes in shallow-water corals. In this study, we present the first multi-colony $\mathrm{Ba}$ isotope calibration from three shallowwater Porites lutea corals with contemporaneous in-situ seawater data from the Singapore Strait. We also report the Ba isotope data in the regional water masses around the study area (i.e., South China Sea, Malacca Strait and Johor River). Singapore water Ba concentrations and isotope compositions show a strong influence of terrestrial inputs, following seasonal salinity and monsoon-driven water-mass mixing between the Malacca Strait and the South China Sea. The coral skeletal $\mathrm{Ba}$ isotopes are consistent between the three coral colonies and the time-series data closely follow the seasonal $\mathrm{Ba}$ isotope variation in seawater. The constant offset between coral skeletal and seawater $\mathrm{Ba}$ isotopes allows for reliable records of seawater Ba isotopes in the past, which could be used as a paleo proxy for tracing salinity and regional water-mass mixing in the Singapore Strait and in other settings.

References

[1] Hemsing, Hsieh, Bridgestock, Spooner, Robinson, Frank \& Henderson (2018), EPSL 491, 183-192.

[2] Geyman, Ptacek, LaVigne \& Horner (2019), EPSL 525, 115751. 